Utah State University

DigitalCommons@USU

1978

\title{
Variation in suckering capacity among and within lateral roots of an aspen clone
}

George A. Schier

Follow this and additional works at: https://digitalcommons.usu.edu/aspen_bib

Part of the Forest Sciences Commons

\section{Recommended Citation}

Schier, George A., "Variation in suckering capacity among and within lateral roots of an aspen clone" (1978). Aspen Bibliography. Paper 4739.

https://digitalcommons.usu.edu/aspen_bib/4739

This Report is brought to you for free and open access by the Aspen Research at DigitalCommons@USU. It has been accepted for inclusion in Aspen Bibliography by an authorized administrator of DigitalCommons@USU. For more information, please contact

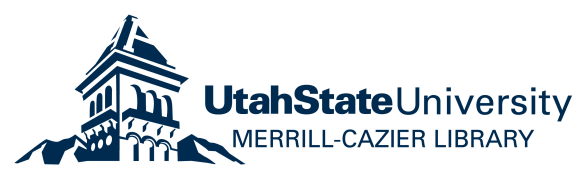




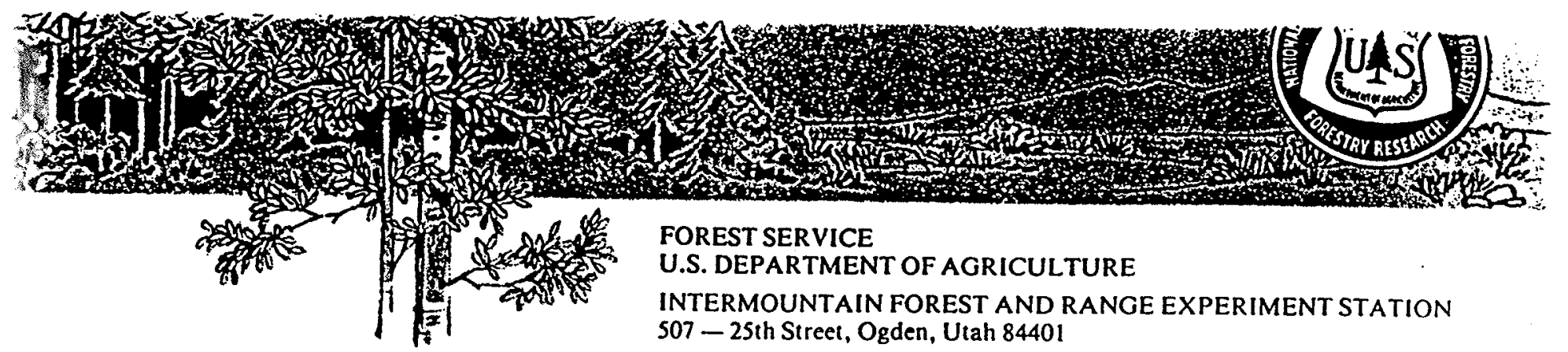

USDA Forest Service

Research Note INT-241

March 1978

VARIATION IN SUCKERING CAPACITY AMONG AND WITHIN LATERAL ROOTS OF AN ASPEN CLONE

George A. Schier ${ }^{1}$

\begin{abstract}
Excised roots were used to determine variation in suckering capacity among and within lateral roots of an aspen (Populus tremuloides Michx.) clone. Differences anong lateral roots were significant. Within segments of a lateral root sucker production showed a high degree of polarity, increasing from the distal to proximal ends. There was no evidence of a gradient in suckering capacity in a segmented root; i.e., distal segments were not significantly different from proximal ones. This indicated that aging was not a factor regulating suckering within lateral roots. Sucker production was not affected by root length.
\end{abstract}

KEYWORDS: Populus tremuloides, aspen, root suckers, adventitious shoots, polarity.

Many investigators have found large interclonal differences in the relative capacity of aspen (Populus tremuloides Michx.) to produce root suckers (Farmer 1962; Maini 1967; Schier 1974; Steneker 1972; Tew 1970; Zufa 1971). However, only Steneker (1972) has studied intraclonal variation in sucker production. When he propagated suckers from root cuttings collected from various parts of a clone, he found significant differences in numbers of suckers produced by the ramets. He also observed a large variation in numbers of suckers produced on cuttings from the same ramet and from the same lateral root.

lPlant Physiologist, located at the Intermountain Station's Forestry Sciences Laboratory, Logan, Utah. 
My objective was to examine within-clone variation in sucker production to deter-
mine (1) if there are significant differences between lateral roots in their ability produce root suckers, and (2) if there are gradients in sucker roots in their ability to roots. Sucker production along a lateral gradients in sucker production along lateral 1967; Steneker and Walters 1971); that is root is strongly influenced by polarity (Maini imal (end toward stem) than on the distal (end targer number of suckers arise on the proxThis gradient is believed to be caused (end toward root apex) halves of root segments. ulators. However, age-related changes by the polar movement of endogenous growth regstems. An aging gradient may exist in may also cause polarity in roots, as they do in end, and chronologically oldest part of a root may be the first-initiated, proximal different from its more recently formet may be morphologically and physiologically are difficult to root, while the formed distal end. Generally, upper portions of stems (Heuser 1976). In a similar manner, cuttings retain the capacity to initiate roots stem may produce more suckers than cuttings from sections of lateral roots near the

\section{METHODS}

In the summer of 1975, roots were excavated from an area of approximately 0.1 ha of Logan, Utah. Single clone in the Wasatch Mountains on the Cache National Forest east were excised from 27 different lateral roots defects (cankers, scars, decay, etc.) roots. Portions of the root sections free of soil. The proximal ends of the segments were cut into $10 \mathrm{~cm}$ segments and washed free of eral root recorded. The segments were were marked and their sequence within the lat$54 \mathrm{~cm})$ in which they were planted to an average depth of $1-1 / 2 \mathrm{~cm}$ in moistened vermicu-
lite. The trays were placed in a greenhouse where the between $15^{\circ}$ and $25^{\circ} \mathrm{C}$, and were watered were removed from the trays and the number of such day. After 6 weeks, the cuttings proximal and distal half of each root segment recorded. sucker on each segment was measured.

In the summer of 1976, a second root collection was from a different area within the same aspen clone. This time single root sections $50 \mathrm{~cm}$ in length and 1 to $2 \mathrm{~cm}$ were randomly divided into three groups severed from 60 different lateral roots. These the following treatments: (1) un groups of 20 sections each and each group given one of $25 \mathrm{~cm})$; and (3) cut into five 10-cm (1 $50 \mathrm{~cm}) ;(2)$ cut into two $25-\mathrm{cm}$ segments (2 by marked) from each treatment were planted sections were arranged in the sequence in which of 10 trays. The segments from cut tivated by the same procedures as before. Six weeks after cut. Root sections were culweight of suckers exceeding $5 \mathrm{~mm}$ in height were determined.

Differences in sucker production caused by either treatment or origin were tested by analysis of variance. Significance of differences between ranked means was determined by Keuls' method (Snedecor 1956). A square root transformation was applied to
sucker numbers prior to analysis.

\section{RESULTS}

\section{Long Root Sections}

The length of the lateral root sections excavated ranged from 51 to $412 \mathrm{~cm}^{\circ}$ (mean, $182 \mathrm{~cm})$. Diameters of the defect-free root segments $(10 \mathrm{~cm})$, cut from the root sections, ranged from 8 to $24 \mathrm{~mm}$ (mean, $16.2 \mathrm{~mm}$ ). There was not much taper within the long ropesegments within a lateral root was only $4.4 \mathrm{~mm}$. 

Table 1.- Variation among lateral roots within an aspen clone in the mean
number of suckers per segment $(10 \mathrm{~cm})$ and mean height of tallest
suckers per segment

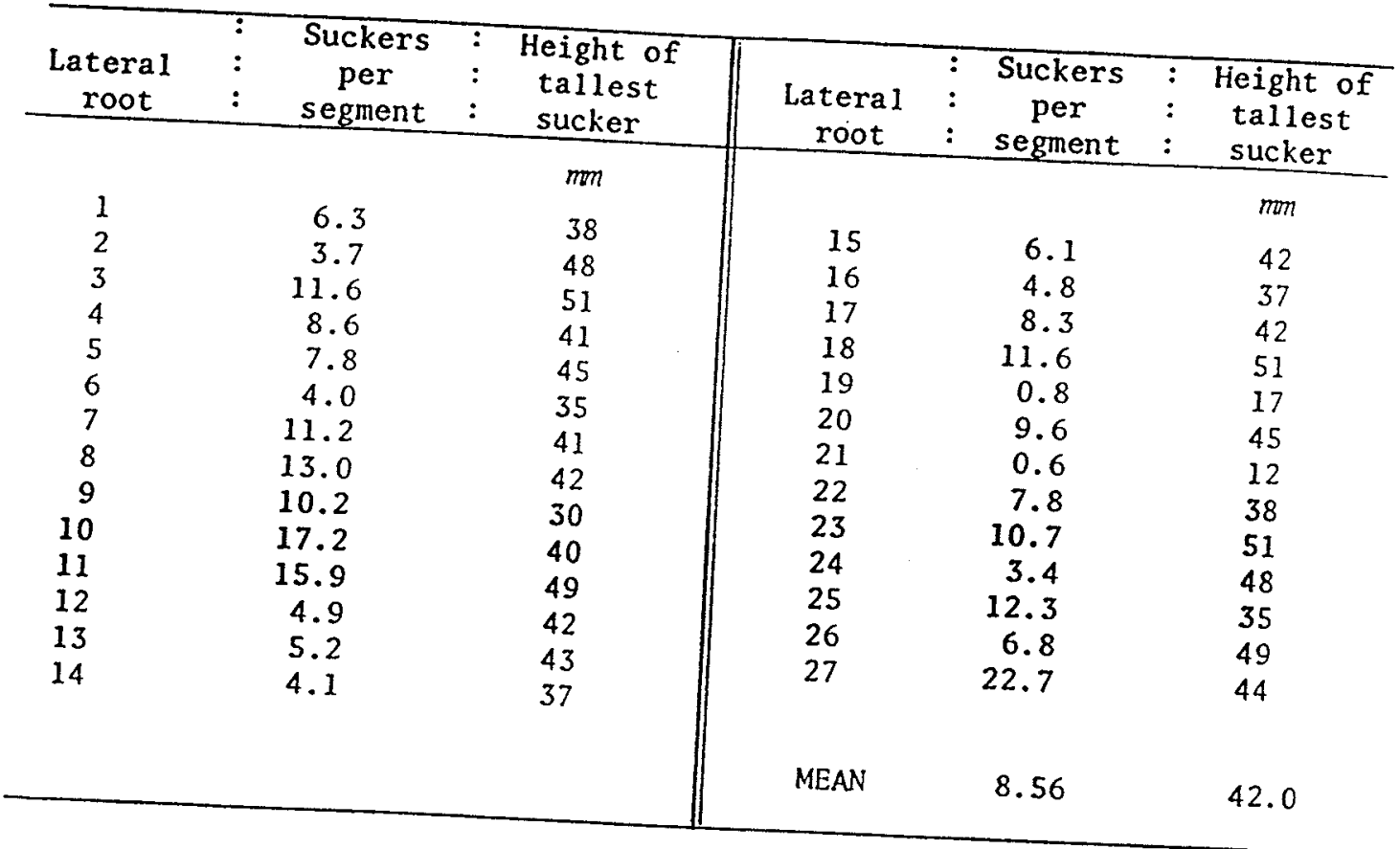

The difference among lateral roots in both number and height of suckers (table 1) was highly significant (1 percent level). Suckering was height of suckers (table 1) significant " tor paired replicates showed that the prost was not related to root diameter. arose from the suckers than the distal halves. Sixty-four of root segments produced evidence of a proximal ends and only 36 percent from the four percent of all suckers evidence of a gradient in suckering capacity ant from the distal ends. There was no number of suckers produced from segments in the proxim lengths of lateral roots. Mean tions were: proximal, 8.36; distal, 8.75 in the proximal and distal halves of root seccapacity between adjacent segments than between dist expect less variation in suckering

Effect of Root Length

Effect of root length on number and dry weight of suckers produced was as follows:

\begin{tabular}{ccc} 
Treatment & $\begin{array}{c}\text { Suckers per } \\
\text { section }\end{array}$ & $\begin{array}{c}\text { Dry we } \\
\text { per su }\end{array}$ \\
\hline & & $(m g)$ \\
$1 \times 50 \mathrm{~cm}$ & 51.0 & \\
$2 \times 25 \mathrm{~cm}$ & 55.9 & 14.4 \\
$5 \times 10 \mathrm{~cm}$ & 39.7 & 12.9 \\
& &
\end{tabular}

Cutting $50-\mathrm{cm}$ lateral root sections into segments $(10$ or $25 \mathrm{~cm}$ ) did not significantly affect number or dry weight of suckers produced by the sections. Within each of the three treatments $(1 \times 50 \mathrm{~cm}, 2 \times 25 \mathrm{~cm}$, or $5 \times 10 \mathrm{~cm})$, differences among lateral 
Table 2.--Distribution of suckers along 50-cm sections of out and uncut aspen roots (proximal end at 0 , distal end at $50 \mathrm{~cm}$ )

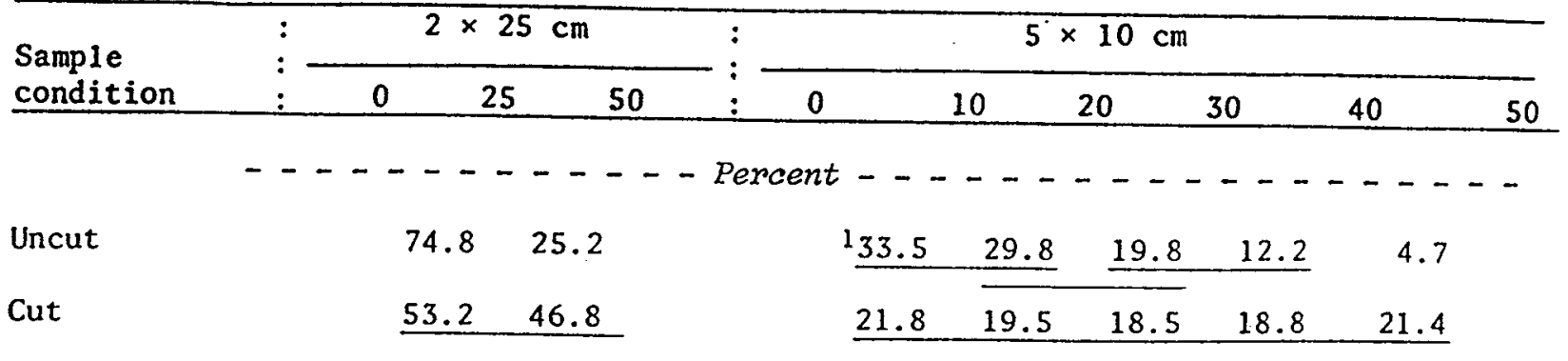

${ }^{1}$ Underlined percentages are not significantly different from each other.

root sections were highly significant (1 percent level). Sucker numbers did not differ significantly between proximal and distal root segments (table 2). However, within uncut sections there was a distinct gradient in suckering capacity; the number of suckers increased along the root from the distal to the proximal end.

\section{DISCUSSION}

Steneker and Walters (1971) also found that length of root cuttings usually did not significantly affect sucker production. However, they found that cutting 36-inch $(91.4-\mathrm{cm})$ root sections into $6-$ inch $(15.2-\mathrm{cm})$ segments significantly reduced mean sucker heights. They also found more suckers on the proximal three segments than on the distal three segments of cut 36 -inch root sections, although polarity was not as evident as in uncut roots.

The polarity of sucker formation on excised aspen roots appears to be caused by physiological factors unrelated to aging. If aging had affected suckering, then gradients in suckering capacity would have occurred along segmented lateral roots. Polarity in roots is usually attributed to the transport of auxin toward root tips (Batra and others 1975; Robinson and Schwabe 1977). Auxin, which suppresses suckering in roots of intact plants, breaks down after the roots are excised (E1iasson 1971; Schier 1973c, 1975). Suckers are then able to develop. Polar movement of the residual auxin in segments probably causes higher concentrations in the distal than in the proximal halves, so the distal halves produce fewer suckers. Cytokinins, which stimulate shoot formation, may also influence the polarity shown in sucker development because these hormones move in a proximal direction (El-Saidi 1971; Wareing and Phillips 1970).

Most suckers that arise on aspen roots appear to develop from suppressed shoot primordia (Schier 1973b). Therefore, variation in the capacity of lateral roots to sucker is probably caused primarily by differences in numbers of primordia. Some roots may have many more primordia than others because they are exposed to.injuries that stimulate primordia formation.

Generally, roots vary in sensitivity to stimuli that initiate primordia because of differences in hormone levels and ratios, water content, and concentration of nutrients. Two factors that may affect the physiological condition of lateral roots are microclimate and position in the clonal root system. Temperature, an important micro-climatic variable, varies with soil depth and exposure to radiation. The position of a lateral root in the root system will determine its location with respect to ramets of 


\begin{abstract}
various ages and vigor. This will determine the quantity of carbohydrates and auxins a major portion of the suckers are initiated after clones have roots with few primordia; cuttings from these clones are probably physiologically preconditioned 1973a). Root opment by the factors mentioned. Early growth of suckers of carbohydrate reserves (Schier and Zasada 1973).

Any sampling method used to estimate suckering capacity of aspen clones

into consideration the large within-clone suckering capacity of aspen clones must take that I have found to work well is to collo variation in sucker production. A procedure withir a clone. Using this procedure 1 have found cuttings from 30 or more locations capacities among clones (Schier 1974).
\end{abstract}


Batra, M. W., K. L. Edwards, and T. K. Scott.

1975. Auxin transport in roots: Kcott.

In: The development and roots: its characteristics and relationship to growth. p. 299-325.

Eliasson, L.

1971. Growth regulators in Populus tremula III. Variation of auxin and inhibitor level in roots in relation to root sucker formation. Physiol. Plant. 25:118-212.

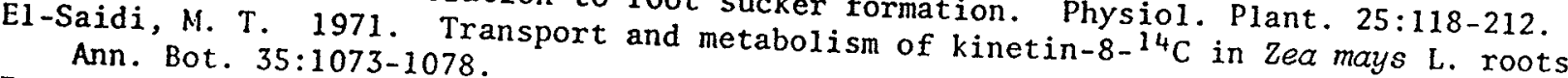
Farmer, R. E., Jr.

1962. Aspen root sucker formation and apical dominance. For. Sci. 8:403-410.

1976. Juvenility and rooting cofactors. In: Symposium on juvenility in woody perennials. Acta Hort. 56:251-261.

Maini, J. S.

1967. Variation in the vegetative propagation of PopuZus in natural populations.
Bull. Ecol. Soc. Am. 48(2):75-76.

Robinson, J. C., and W. W. Schwabe.

1977. Studies on the regeneration of apple cultivars from root cuttings. II.

Schier, G. A.

1973a. Effects of gibberellic acid and an inhibitor of gibberellin action on sucker-

ing from aspen root cuttings. Can. J. For. Res. 3:39-44.

Schier, G. A.

1973b. Origin and development of aspen root suckers. Can. J. For. Res. 3:45-53.
Schier, G. A.

1973c. Seasonal variation in sucker production from excised roots of Populus

Schier, G. A.

1974. Vegetative propagation of aspen: clonal variation in suckering from cuttings and in rooting of sucker cuttings. Can. J. For. Res. 4:565-567.

Schier, G. A.

1975. Promotion of sucker development on Populus tremuloides root cutting by an antiauxin. Can. J. For. Res. 5:338-340

Schier, G. A., and J. C. Zasada.

1973. Role of carbohydrate reserves in the development of root suckers in

Populus tremuloides. Can. J. For. Res. 3:243-250.

Snedecor, G. W.

1956. Statistical methods. Iowa State Coll. Press, Ames, p. 253.
Steneker, G. A.

1972. Size and suckering of trembling aspen clones in Manitoba. Ph.D. thesis,

Steneker, G. A., and M. A. Walters.

1971. The effect of root length upon the suckering of trembling aspen. Environment

Canada. For. Serv. North. For. Res. Cent. Inf. Rep. A-X-46, $11 \mathrm{p}$.
R. K.

Tew, R. K.

- 1970. Root carbohydrate reserves in vegetative reproduction of aspen. For. Sci.

Wareing, P. F., and I. D. J. Phillips.

1970. The control of growth and differentiation in plants. Pergamon Press, New
York. $303 \mathrm{p}$. Zufa, L.

1971. A rapid method for vegetative propagation of aspens and their hybrids.
For. Chron. 47:36-39. 